\title{
Health expenditure, child and maternal mortality nexus: a comparative global analysis
}

Rezwanul Hasan Rana ${ }^{1 *}$, Khorshed Alam ${ }^{1}$ and Jeff Gow ${ }^{1,2}$

\begin{abstract}
Background: This paper provides empirical evidence on how the relationship between health expenditure and health outcomes varies across countries at different income levels.

Method: Heterogeneity and cross-section dependence were controlled for in the panel data which consist of 161 countries over the period 1995-2014. Infant, under-five and maternal mortality along with life expectancy at birth were selected as health outcome measures. Cross-sectional augmented IPS unit root, panel autoregressive distributed lag, Dumitrescu-Hurlin and Toda-Yamamoto approach to Granger causality tests were used to investigate the relationship across four income groups. An impulse response function modelled the impact on health outcomes of negative shocks to health expenditure.

Results: The results indicate that the health expenditure and health outcome link is stronger for low-income compared to high-income countries. Moreover, rising health expenditure can reduce child mortality but has an insignificant relationship with maternal mortality at all income levels. Lower-income countries are more at risk of adverse impact on health because of negative shocks to health expenditure. Variations in child mortality are better explained by rising health expenditure than maternal mortality. However, the estimated results showed dissimilarity when different assumptions and methods were used.

Conclusion: The influence of health expenditure on health outcome varies significantly across different income levels except for maternal health. Policymakers should recognize that increasing spending has a minute potential to improve maternal health. Lastly, the results vary significantly due to income level, choice of assumptions (homogeneity, crosssection independence) and estimation techniques used. Therefore, findings of the cross-country panel studies should be interpreted with cautions.
\end{abstract}

\section{Background}

Over the past few decades the world has seen substantial improvements in health outcomes (HO). This has coincided with rising health expenditure (HE). Global per capita HE has increased from US\$587 in 2000 to US\$1299 in 2015 in real terms [1]. Globally, since 1990 to 2013, the under-five mortality rate (U5MR) decreased by $49 \%$, the reduction in maternal mortality ratio was $45 \%$ and life expectancy at birth (LFE) increased from 64 years to 71 years [2].

\footnotetext{
*Correspondence: rezwanul_54@yahoo.com; rezwanulhasan.rana@usq.edu.au ${ }^{1}$ School of Commerce, University of Southern Queensland, Toowoomba, Australia

Full list of author information is available at the end of the article
}

A large literature has examined the variations in $\mathrm{HO}$ and HE across countries [3-6]. Despite these efforts the causal relationship between $\mathrm{HE}$ and $\mathrm{HO}$ is still not clear. Researchers are yet to confirm whether income plays a key moderating role in deciding the direction of causality. Moreover, past empirical studies have overlooked the impact on HO due to a negative shock to HE. The question remains: how much variation in $\mathrm{HO}$ can be explained by HE? Equally important is to understand the effect of the assumptions of homogeneity and cross-section independence on the empirical findings of earlier studies. Lastly, wide disagreement regarding the variables which most accurately measure $\mathrm{HO}$ exists $[7,8]$.

It is usually assumed that rising HE will automatically improve HO. Nonetheless, the evidence for a causal 
association between the two variables remains inconclusive. Some studies have found no causal relationship or an insignificant association [6, 9]. Gupta et al. [10] sampled 50 developing and transition countries for 1993 and 1994 and concluded that increased HE reduces IMR and the under-five mortality rate (U5MR). Crémieux et al. [11] found that lower HE was associated with increased IMR and decreased LFE in selected Canadian provinces. Other panel data studies have found a significant association and concluded that HE plays an important role in improving $\mathrm{HO}[12,13]$.

Other studies have found no evidence that total $\mathrm{HE}$ has any significant impact on $\mathrm{HO}[9,14,15]$. Therefore, whether $\mathrm{HE}$ can significantly influence the different measures of $\mathrm{HO}$ remains unclear, and warrants further investigations.

Past studies have shown contradictory findings on the scale of association across low and high-income countries. Bradley et al. [16] and Gupta et al. [10] concluded that public HE provides a higher return to $\mathrm{HO}$ for poor countries than for high-income countries. Similarly, Self and Grabowski [17] found that HE has a significant impact on health only in low and middle-income countries. Furthermore, Bidani and Ravallion [18] and Nicholas et al. [19] stated that public HE is useful for the poor but not for the non-poor (high-income) in improving HO. Nicholas et al. [19] also concluded that private $\mathrm{HE}$ has no significant impact in reducing child and maternal mortality in 40 countries of sub-Saharan Africa. Similar results were also found by Anyanwu and Erhijakpor [20] for 47 African countries and Farag et al. [12] for 133 low and middle income countries. Contradicting these findings, Hall et al. [13] examined OCED countries, Jakovljevic et al. [21] with 24. European Union countries and Vavken et al. [22] with selected European Union countries all concluded that HE has had a significant impact on HO. Again, Bokhari et al. [23] in developing countries found a significant relationship between HE and maternal mortality rate (MMR). Nixon and Ulmann [5] indicated that HOs are significantly influenced by factors like diet, lifestyle and the environment. These differ significantly amongst high and low-income countries, subsequently, the influence of HE on health should also vary. Therefore, drawing a conclusion as to whether $\mathrm{HE}$ influences $\mathrm{HO}$ equally at all income levels is still not clear.

Noticeably, the literature suffers from several methodological shortcomings. This study will make some significant methodological contributions to overcoming that deficit. Firstly, no previous studies have used a comprehensive sample of panel data over a substantial time period and a large number of countries, representing all income levels and regions. Previous studies either used a small number of countries or smaller time periods. Again, the time series and panel analyses in earlier research assumed homogeneity and cross-section independence in the data [17, 24].
However, these assumptions are not always valid for panel data analyses. The results of these studies are not robust if they fail to account for unobserved heterogeneity [25]. Moreover, the presence of cross-section dependence in panel data can seriously compromise the stationarity of the variables and cause the regression results to be spurious [26]. This issue will be addressed by using recently developed estimation techniques (cross-sectional augmented IPS (Im-Pesaran-Shin) test and Dumitrescu-Hurlin (DH) causality test for heterogeneous panel) to overcome this problem. Lastly, no previous study has examined the impact on $\mathrm{HO}$ of negative shocks to HE. Impulse response function (IRF) and forecast-error variance decomposition (FEVD) tests are innovative methods for finding sources of information and transmission of information in a dynamic panel analysis [27]. Therefore, these tests will be employed to understand the responsiveness of $\mathrm{HO}$ to negative shocks in $\mathrm{HE}$ at different income levels.

The objective of this study is to examine these relationships using a comprehensive data set of 161 countries, divided into four income groups (see Appendix). By comparing the respective conclusions from each income group, it will be possible to examine the moderating role of income on the HE-HO nexus. Robustness of results will be enhanced by using new, appropriate estimation techniques at each stage. To the best of authors' knowledge, no previous studies examined the $\mathrm{HO}$ and $\mathrm{HE}$ relationship using panel data have utilised these techniques. Lastly, an examination of which of four HO measures (IMR, U5MR, MMR and LFE) are more responsive to changes in $\mathrm{HE}$ at different income levels will be made.

This paper has of five sections. After this introductory part, the method and model structure, data and estimation strategy is presented in section "Methods". Section "Results" reports the results whilst a discussion and some policy implications of these are presented in section "Discussion". Lastly, section "Conclusions" will offer conclusions and outline some limitations of the study.

\section{Methods \\ Model structure}

The model structure has been derived from the Grossman demand for health model [28].

The Grossman model specifies the gross investment in stock of health with the following equation,

$$
\mathrm{I}_{\mathrm{t}}=\mathrm{I}_{\mathrm{t}}\left(\mathrm{M}_{\mathrm{t}}, \mathrm{TH}_{\mathrm{t}}, \mathrm{E}_{\mathrm{t}}\right)
$$

In the above equation, $\mathrm{M}_{\mathrm{t}}, \mathrm{TH}_{\mathrm{t}}$ and $\mathrm{E}_{\mathrm{t}}$ imply medical care, time input in gross investment function and stock of human capital, respectively. Any changes to these variables also changes the net investment in stock of health. Nonetheless, medical care, being the most important market good component of the gross investment function [28], has 
prices and costs associated with it. Therefore, holding other things constant, higher utilisation of medical care is related to higher health care expenditure (HE) and vice versa. Hence, the volume of medical inputs used is a function of the level of $\mathrm{HE}$,

$$
\mathrm{M}_{\mathrm{t}}=f\left(\mathrm{HE}_{\mathrm{t}}\right)
$$

Therefore, the current study assumes that with the growth of per capita health expenditure, health status or outcomes also increases, significantly.

\section{Data}

A heterogeneous panel data method for investigating the causal relationship between $\mathrm{HE}$ and $\mathrm{HO}$ is adopted. The data is annual for 161 countries for the period 1995 to 2014. The source of the data set are the World Development Indicators [1] and the Global Health Observatory [29]. HE per capita was used as the predictor variable for the cointegration tests. Four variables will be used as a proxy for measuring $\mathrm{HO}$ following the previous studies of Wang [30], Bokhari et al. [23] and Anyanwu and Erhijakpor [20]. The variables are infant mortality rate (IMR) per 1000 live births, under-five mortality rate (U5MR) per 1000 live births, maternal mortality ratio (MMR) per 100,000 live births and life expectancy (LFE) at birth. Due to the unavailability of reliable data, other measures of HO like 'quality-adjusted life years' or 'potential years of life lost' were not used.

Table 1 provides a brief comparison of the changes in values of the variables from 1995 to 2014. Noticeably, during these 20 years, real HE per capita increased almost three fold, LFE increased by more than seven years, IMR and U5MR reduced by half, and MMR has reduced by approximately two-fifths.

\section{Estimation strategy}

The objective of this study is to extend the existing knowledge by using a heterogeneous panel data analysis instead of a homogenous approach, along with the assumption of cross-section dependence. Diagnostic tests confirmed that measures of HO (IMR, MMR, U5MR and LFE) and HE

Table 1 Summary statistics (Global)

\begin{tabular}{llllllll}
\cline { 1 - 2 } Year & & 1995 & 2014 & 1995 & 2014 & 1995 & 2014 \\
\cline { 1 - 2 } Variables & Obs & Mean & Mean & Std.Dev & Std.Dev & Max & Max \\
\hline HE & 161 & 443.4 & 1202.5 & 819.8 & 1971.8 & 4308.5 & 9673.5 \\
LFE & 161 & 54.5 & 61.7 & 12.2 & 10.6 & 73.5 & 76.7 \\
U5MR & 161 & 64.5 & 30.9 & 65.2 & 32.6 & 279.5 & 162.2 \\
IMR & 161 & 43.7 & 23.2 & 37.4 & 21.8 & 153.4 & 98.8 \\
MMR & 160 & 277.9 & 157.8 & 403.1 & 227.2 & 2900 & 1410
\end{tabular}

Source: World Bank (2016)

Notes: Obs Number of observations, Max Maximum value and HE Health expenditure per capita, LFE Life expectancy at birth, USMR Under-five mortality rate, IMR Infant mortality rate and MMR Maternal mortality rate data contain heterogeneity and indicate a cross-section dependence problem.

\section{Cross-section dependence and heterogeneity in panel data}

Cross-section dependence generally arises when the error-terms of the adjacent units (country, company or state) are correlated, often due to spillover effects [31] or unobserved common factors [32]. Many previous studies have investigated the issue of cross-section dependence in panel data and cautioned against ignoring the problem [33]. The issue can create considerable difficulty for the unit root test [26], and may lead to inaccurate estimates [34] and biased standard errors [35]. There are several reasons (spatial correlation, distance, and common unobserved elements) which may be responsible for the dependence [36].

Panel data studies with $\mathrm{N}>\mathrm{T}$ often fail to provide evidence for the homogeneity of the pooled data [37] which means that observations from the identical units tend to be much more similar compared to the observations of different units [38]. According to Hauck and Zhang [39] common omitted variables or events such as, global shocks impact each observational unit asymmetrically. The presence of heterogeneity creates a minor nuisance for inferences [31] and may lead to inconsistent estimates of the parameters [40].

\section{Panel unit root tests}

In the first step of the analysis, the stationarity of the data have been examined with the cross-sectional augmented IPS (CIPS) unit root tests [41]. The third generation unit root test allows heterogeneity of the autoregressive coefficients and gives consistent results in the presences of cross-section dependence in the panel data [42]. In addition, the HT (Harris-Tsavails) panel unit root test was used [43]. It was developed specifically for data sets with large $(N)$ and small $(T)$ with the option of controlling cross-sectional means.

\section{Panel cointegration tests}

In the second stage, the autoregressive distributed lag (ARDL) (mean group) technique was used to understand the cointegration relationship. According to Pesaran et al. [44], the ARDL can incorporate the heterogeneous panel into the error-correction model. The mean group (MG) estimation technique allows the long-run and short-run effects to be different and be heterogeneous across panel units [45]. The ARDL model is expressed as:

$$
\begin{aligned}
\Delta H O_{i t}= & \varnothing_{i} H O_{i, t-1}+H E_{i, t-1} \beta_{i}+\sum_{j=1}^{p-1} \alpha_{i j} \Delta H O_{i, t-1} \\
& +\sum_{j=0}^{q-1} \partial_{i j} \Delta H E_{i, t-j}+\varepsilon_{i t}+\cup_{i t}
\end{aligned}
$$

where $H O$ is the dependent variable with lag $p$ and $H E$ is the independent variable with $q$ number of lags. $\beta_{i}$ is the long-run coefficient and $\varnothing_{i}$ represents scalar coefficients 
on the lagged dependent variable which measures the speed of adjustment to the long-run equilibrium. $\partial$ is the short-run coefficient for independent variable and $\alpha$ is for the dependent variable. In addition, subscript $i$ and $t$ indicate the country and time indexes of the panel data set respectively. To determine the lag length, the standard lag selection criteria of Akaike information criterion (AIC) and Bayesian information criterion (BIC) were used. ARDL techniques are used to examine the cointegrating relationship among variables which are not stationary of the same order $[44,46]$.

Further the FMOLS (Fully modified ordinary least squares) method developed by Pedroni [47] which incorporates the semi-parametric correction of the OLS estimation suggested by Hansen and Phillips [48] is also utilised as the majority of the data are stationary at $I(1)$ and the approach provides reliable estimates for small samples [49]. The cointegration system for panel data is:

$$
H O_{i t}=\beta_{0}+\mathrm{HE}_{i t} \beta_{i}+\varepsilon_{i t}
$$

and

$$
H E_{i t}=\mathrm{HE}_{i, t-1}+\mathrm{v}_{i t}
$$

where the vector error process $\vartheta_{i t}=\left({ }_{i t}, \mathrm{v}_{i t}\right)$ is stationary with asymptotic covariance matrix represented by $\Omega_{\mathrm{i}}$. The variables, $H O_{i}$ and $H E_{i}$, have long-run cointegration with cointegrated vector $\beta_{i}$, if the $H E_{i t}$ is integrated of $I(1)$ [47]. In addition, FMOLS uses a semi-parametric correction for endogeneity and serial correlation. Moreover, the group mean estimator of FMOLS allows for a higher degree of heterogeneity to be present in the dynamics underlying dependent and independent variables $[50,51]$.

Based on Pedroni [47], the FMOLS estimator is:

$$
\begin{aligned}
\hat{\beta}_{i, F M O L S}=\mathrm{N}^{-1} \sum_{i=1}^{N} & \left(\sum_{i=1}^{T}\left(H E_{i t}-\overline{H E}_{i t}\right)^{2}\right)^{-1} \\
& \left(\sum_{i=1}^{T}\left(H E_{i t}-\overline{H E}_{i t}\right) H O_{i t}^{*}-T_{\tau_{i}}\right)
\end{aligned}
$$

where $H O_{i t}^{*}=\left(H E_{i t}-\overline{H E}_{i t}\right)-\left(\frac{\hat{\Omega}_{21 i}}{\hat{\Omega}_{221}}\right) \Delta H E_{i t}$ and

$$
\hat{\tau}_{i}=\hat{\Gamma}_{21 i}+\hat{\Omega}_{21 i}^{0}-\left(\frac{\hat{\Omega}_{21 i}}{\hat{\Omega}_{221}}\right)\left(\hat{\Gamma}_{22 i}+\hat{\Omega}_{22 i}^{0}\right)
$$

where $\hat{\Omega}$ represents the covariance and $\hat{\Gamma}$ indicates the sums of autocovariance acquired from the long-run covariance matrix. In addition, $\hat{\boldsymbol{\tau}}_{i}$ is the moderator to correct for the autocorrelation which arises from the heterogeneity dynamics determining dependent and independent variables in the short run process [49].

\section{Panel granger causality tests}

Next, panel causality tests suggested by Toda and Yamamoto [52] (TY) and Dumitrescu and Hurlin [53] $(\mathrm{DH})$ were performed. Both are modified versions of the causality test suggested by Granger [54]. According to Dumitrescu and Hurlin [53], the heterogeneous panel causality test is designed for bi-variates models of stationary and nonintegrated variables. The following DH non-causality equations were examined:

$$
\begin{aligned}
& \Delta H O_{i t}=\propto+\sum_{k=1}^{K} \beta_{i k} \Delta H O_{i, t-k}+\sum_{k=1}^{K} \varnothing_{i k} \Delta H E_{i, t-k}+\epsilon_{i, t} \\
& \Delta H E_{i, t}=\propto+\sum_{k=1}^{K} \beta_{i k} \Delta H E_{i, t-k}+\sum_{k=1}^{K} \varnothing_{i k} \Delta H O_{i, t-k}+\epsilon_{i, t}
\end{aligned}
$$

where $K$ indicates the number of lag length in the balanced panel with $\alpha$ is the intercept and slope coefficients are $\beta$ and $\varnothing$. As the test is sensitive to lag length [55], the formula $T>5+2 X$ was used to determine the minimum number of lags where $X$ signifies the minimum number of time needed at each number of lags and $T$ is the time period [56]. The modified Wald (MWALD) causality test proposed by Toda and Yamamoto [52] is also used as it reduces the probability of inaccurate identification of the order of integration in the series by ignoring any possibility of non-stationarity and lack of cointegration in the panel $[57,58]$. The modified Wald equation is:

$$
\begin{aligned}
\Delta H O_{t}=\alpha_{0} & +\sum_{k=1}^{n} \alpha_{1 k} \Delta H O_{t-k}+\sum_{j=n+1}^{d_{\max }} \alpha_{2 j} \Delta H O_{t-j} \\
& +\sum_{k=1}^{n} \partial_{1 k} \Delta H E_{t-k}+\sum_{j=n+1}^{d_{\max }} \partial_{2 j} \Delta H E_{t-j}+\omega_{1 t} \\
\Delta H E_{t}=\beta_{0} & +\sum_{k=1}^{n} \beta_{1 k} \Delta H E_{t-k}+\sum_{j=n+1}^{d_{\max }} \beta_{2 j} \Delta H E_{t-j} \\
& +\sum_{k=1}^{n} \varnothing_{1 k} \Delta H O_{t-k}+\sum_{j=n+1}^{d_{\max }} \varnothing_{2 j} \Delta H O_{t-j}+\omega_{2 t}
\end{aligned}
$$

The Toda-Yamamoto test increases the accurate order of the VAR system, $n$, precisely to the maximum order of integration, $d_{\max }$ [58]. Lastly, the approach uses seemingly unrelated regression (SUR) to estimate the model [59].

These two causality tests (DH and TY approach) are appropriate given the panel was heterogeneous, stationary at different levels (in some cases) and not cointegrated in the long-run for some of the models.

Finally, to measure the impact of an unexpected shock in the vector autoregressive (VAR) model, IRF and FEVD tests were performed. According to Swanson and Granger [60], IRF and FEVD tests proposed by Sims [61] are an integral part of the VAR estimations. The IRF examines the impact of shocks in cross-section by tracing the marginal effect of a shock to one variable in the system for the response variable 
[25]. On the contrary, FEVD shows the fraction of the changes in the dependent variable that is subject to their own shocks against the shocks to the impulse variable [62]. For further discussion on the methods of IRF and FEVD (Sims [61], Lütkepohl and Krätzig [63], and Brooks [62]).

Prior to these tests, the stability condition of the VAR was checked with the VAR stability test.

\section{Diagnostic tests}

To identify serial correlation in the panel data model the test developed by Wooldridge [31] is used. This test uses less assumptions, which are more robust and appropriate for micro panels. To examine the level of cross-section dependence $(\mathrm{CD})$ in the panel data, the $\mathrm{CD}$ test of Pesaran [64] was performed. The test assumes zero mean for fixed values of $T$ and $N$, and appropriate for heterogeneous, non-stationary and dynamic panel models [65]. In addition, modified Wald test for group wise heteroscedasticity and residual normality test [66] were conducted.

\section{Results}

\section{Panel unit root tests}

The results from cross-sectional augmented IPS (CIPS) and HT panel unit root tests for the level and first

Table 2 Panel unit root test results

\begin{tabular}{|c|c|c|c|c|c|c|c|c|c|c|}
\hline \multicolumn{11}{|c|}{ Cross-sectional Augmented IPS (CIPS*) (Trend) } \\
\hline \multicolumn{3}{|l|}{ Dep.Variables HE } & \multicolumn{2}{|l|}{ IMR } & \multicolumn{2}{|l|}{ MMR } & \multicolumn{2}{|l|}{ U5MR } & \multicolumn{2}{|l|}{ LFE } \\
\hline Income Groups & Level & 1st Diff & Level & 1st Diff & Level & 1st Diff & Level & 1st Diff & Level & 1st Diff \\
\hline $\mathrm{GL}$ & -2.13 & $-3.74^{*}$ & -2.42 & $-3.31^{*}$ & -2.54 & $-4.26^{*}$ & -2.65 & $-2.88^{*}$ & $-2.95^{*}$ & $-3.83^{*}$ \\
\hline LY & -2.70 & $-4.27^{*}$ & -2.38 & $-2.72^{*}$ & -1.90 & $-3.33^{*}$ & -2.04 & $-2.71^{*}$ & $-2.85^{*}$ & $-2.77^{*}$ \\
\hline LM & -2.44 & $-3.44^{*}$ & -2.53 & $-2.98^{*}$ & -2.09 & $-3.16^{*}$ & $-3.23^{*}$ & $3.86^{*}$ & $-3.11^{*}$ & $-3.98^{*}$ \\
\hline HM & -2.52 & $-3.54^{*}$ & -2.12 & $-2.95^{*}$ & -2.36 & $-4.42^{*}$ & -2.17 & $-2.96^{*}$ & $-3.98^{*}$ & $-4.13^{*}$ \\
\hline $\mathrm{HY}$ & -1.49 & $-2.94^{*}$ & -2.02 & $-3.09^{*}$ & $2.75^{*}$ & $-5.12^{*}$ & -2.21 & $-3.02^{*}$ & $-2.73^{*}$ & $-4.42^{*}$ \\
\hline \multicolumn{11}{|c|}{ Harris-Tsavalis (HT) (Trend) } \\
\hline Dep. Variables HE & & & IMR & & MMR & & U5MR & & LFE & \\
\hline Income Groups & Level & 1st Diff & Level & 1st Diff & Level & 1st Diff & Level & 1st Diff & Level & 1st Diff \\
\hline GL & 5.51 & $-16.51^{*}$ & 8.52 & $-5.42^{*}$ & 12.34 & $9.13^{+}$ & $-12.27^{*}$ & $-41.78^{*}$ & 13.98 & $6.05^{+}$ \\
\hline LY & 1.07 & $-13.35^{*}$ & 0.61 & $-14.90^{*}$ & 6.02 & $5.22^{+}$ & $-13.20^{*}$ & $-27.22^{*}$ & 8.87 & $6.69^{+}$ \\
\hline LM & 4.17 & $-12.82^{*}$ & 7.12 & $5.54^{+}$ & 5.71 & $-5.79^{*}$ & 6.09 & $-7.17^{*}$ & 12.12 & $10.27^{+}$ \\
\hline $\mathrm{HM}$ & 2.97 & $-10.25^{*}$ & 5.34 & $3.62^{+}$ & 5.92 & $-3.88^{*}$ & 5.93 & 3.29 & 1.68 & $-4.33^{*}$ \\
\hline HY & 3.23 & $-10.26^{*}$ & 6.99 & $-5.16^{*}$ & -0.66 & $-15.58^{*}$ & 6.88 & 5.92 & 4.37 & $-7.24^{*}$ \\
\hline \multicolumn{11}{|c|}{ Cross-sectional Augmented IPS (CIPS*) (Constant) } \\
\hline Dep. Variables HE & & & IMR & & MMR & & U5MR & & LFE & \\
\hline Income Groups & Level & 1st Diff & Level & 1st Diff & Level & 1st Diff & Level & 1st Diff & Level & 1st Diff \\
\hline $\mathrm{GL}$ & $-2.20^{*}$ & $-3.69^{*}$ & $-2.47^{*}$ & $-2.53^{*}$ & $-2.42^{*}$ & $-3.68^{*}$ & $-2.78^{*}$ & $-2.45^{*}$ & -2.12 & $-3.17^{*}$ \\
\hline LY & $-3.16^{*}$ & $-4.37^{*}$ & $-2.78^{*}$ & $-2.45^{*}$ & -1.36 & $-2.50^{*}$ & $-2.39^{*}$ & $2.31^{*}$ & $-3.33^{*}$ & $-2.88^{*}$ \\
\hline LM & $-2.82^{*}$ & $-3.79^{*}$ & $-2.44^{*}$ & $-2.32^{*}$ & -2.09 & $-3.17^{*}$ & $-3.23^{*}$ & $-2.51^{*}$ & -1.14 & $-3.10^{*}$ \\
\hline HM & $-3.25^{*}$ & $-3.57^{*}$ & $-2.30^{*}$ & $-2.61^{*}$ & $-2.63^{*}$ & $-3.80^{*}$ & $-2.42^{*}$ & -1.81 & -1.87 & $-4.18^{*}$ \\
\hline HY & -1.83 & $-3.41^{*}$ & $-2.03^{*}$ & $-3.10^{*}$ & $-2.75^{*}$ & $-4.63^{*}$ & $-2.32^{*}$ & $-3.02^{*}$ & $-2.38^{*}$ & $-4.23^{*}$ \\
\hline \multicolumn{11}{|c|}{ Harris-Tsavalis (HT) (Constant) } \\
\hline Dep. Variables HE & & & IMR & & MMR & & U5MR & & LFE & \\
\hline Income Groups & Level & 1st Diff & Level & 1st Diff & Level & 1st Diff & Level & 1st Diff & Level & 1st Diff \\
\hline $\mathrm{GL}$ & 11.05 & $-54.82^{*}$ & 10.16 & $-64.33^{*}$ & 9.35 & $-27.68^{*}$ & 6.72 & $-98.98^{*}$ & 12.27 & $-27.33^{*}$ \\
\hline LY & 2.51 & $-16.51^{*}$ & 8.51 & $-5.41^{*}$ & 9.34 & $-27.68^{*}$ & 6.72 & $-98.97^{*}$ & 6.88 & $-30.25^{*}$ \\
\hline LM & 4.17 & $-12.82^{*}$ & 7.21 & $-6.35^{*}$ & 3.83 & $-32.64^{*}$ & 5.27 & $-27.17^{*}$ & 7.08 & $1.13^{+}$ \\
\hline HM & 2.87 & $-10.16^{*}$ & 5.27 & $3.57^{+}$ & 1.51 & $-5.46^{*}$ & 5.01 & $-7.91^{*}$ & 6.20 & $-34.49^{*}$ \\
\hline HY & 11.05 & $-54.82^{*}$ & 10.16 & $-64.32^{*}$ & 9.34 & $-27.68^{*}$ & 6.72 & $-98.97^{*}$ & 11.00 & $-27.33^{*}$ \\
\hline
\end{tabular}

Notes: *Significant at the $5 \%$ confidence interval. ${ }^{+}$Not stationary at 1 st difference. The optimal lag used for CIPS* test was based on MBIC and MAIC lag selection criteria. For the CIPS test the results of trend option are presented and the HT test the 'Demean' option was used to control for cross-sectional means. Here, HE Health expenditure per capita, GL Global, LY Low-income, LM Lower-middle, HM Higher-middle and HY High-income countries 
Table 3 Mean group estimation ARDL model

\begin{tabular}{|c|c|c|c|c|c|c|c|c|}
\hline \multirow{2}{*}{$\begin{array}{l}\text { Dep.Variables } \\
\text { Income Groups }\end{array}$} & \multicolumn{2}{|l|}{ IMR } & \multicolumn{2}{|l|}{ MMR } & \multicolumn{2}{|l|}{ U5MR } & \multicolumn{2}{|l|}{$\underline{\text { LFE }}$} \\
\hline & Long & Short & Long & Short & Long & Short & Long & Short \\
\hline$\overline{L Y}$ & $-0.22^{*}(0.04)$ & $-0.01 *(0.01)$ & $0.48^{*}(0.14)$ & $-0.11(0.08)$ & $0.03 *(0.04)$ & $-0.03(0.02)$ & $-0.01^{*}(0.25)$ & $-0.21^{*}(0.03)$ \\
\hline LM & $-0.01(0.03)$ & $-0.04^{*}(0.01)$ & $-0.02(0.04)$ & $-0.26^{*}(0.09)$ & $-0.01(0.04)$ & $-0.07^{*}(0.16)$ & $0.013^{*}(0.08)$ & $-0.44^{*}(0.05)$ \\
\hline HM & $0.124^{*}(0.02)$ & $-0.02^{*}(0.07)$ & $0.05^{*}(0.28)$ & $0.01(0.08)$ & $0.07^{*}(0.04)$ & $-0.03(0.05)$ & $0.04^{*}(0.00)$ & $-0.51^{*}(0.09)$ \\
\hline HY & $0.00 *(0.00)$ & $-0.08^{*}(0.14)$ & $-0.01 *(0.00)$ & $-0.08^{*}(0.05)$ & $0.00^{*}(0.00)$ & $-0.09(0.15)$ & $0.00^{*}(0.00)$ & $-1.15^{*}(0.11)$ \\
\hline
\end{tabular}

Notes: Figures in brackets are the standard errors. * Significant at $5 \%$ level. Lag order is chosen using AIC criterion. The estimated constant terms are significant at $5 \%$ confidence interval for all the model

difference series are presented in Table 2. The CIPS heterogeneous panel unit root test indicated that HEPC, IMR, MMR, and U5MR are stationary at first difference. For higher income group, MMR, and for the lower-middle income group, U5MR is stationary at level. However, LFE is stationary at level and 1st difference for all income group.

The HT test showed similar results to CIPS in most of the cases except for the variable LFE. Interestingly, the test showed IMR for higher-middle and LFE for lower-middle income countries are not stationary either at level or at first difference. Based on these test results the ARDL (MG) test was applied to investigate the long-run association between the measures of IMR, MMR, U5MR and LFE with HE.

\section{Panel cointegration test}

The ARDL test provides efficient estimates when the variables are cointegrated at dissimilar levels $[44,46]$ and report both short-run and long-run relationship between the variables. The findings in Table 3 indicate mixed results. It can be seen that IMR and LFE are cointegrated with HE in the short-run for all income levels. LFE also demonstrated long-run cointegration. However, MMR is cointegrated in the short run only for lower-middle and higher income countries and U5MR for lower-middle income countries. The long run coefficients showed a different picture. All the measures of $\mathrm{HO}$ have a long-run relationship with $\mathrm{HE}$ for low-income, higher-middle, and high-income countries.

To estimate the robustness of the findings of long-run relationship the FMOLS approach was employed. The results of the FMOLS test (Table 4) confirmed the long-run association between $\mathrm{HO}$ and HE. The only exception was MMR, which indicates no long-run cointegration with HE for lower and lower-middle income countries. Therefore, it is concluded that $\mathrm{HO}$ and HE were cointegrated in the long-run, however, the results vary based on the level of income and measures of $\mathrm{HO}$ used.

\section{Granger causality test}

After confirming the long-run association, the VAR Granger panel causality test, the DH panel causality test and TY approach to Granger causality test were performed. The DH and TY approaches provide more reliable results as the panel data is heterogeneous, that is, variables are stationary at different levels and showed mixed results in the cointegration relationship.

In the $\mathrm{DH}$ causality test, $\mathrm{HO}$ and $\mathrm{HE}$ indicated bi-directional causality. Nevertheless, the results differ at different income levels. There are bidirectional relationships for IMR and U5MR with HE for low-income and lower-middle income countries. For high-income countries U5MR has bidirectional causality. The test found no causality for MMR with HE at any income level.

Again, the TY approach also illustrated bi-directional causality for IMR and U5MR with HE only for low-income countries. In addition, there is uni-directional relationship running from HE to IMR for high-income and lower-middle income countries. Thus, according to the TY causality test, HE Granger causes IMR and U5MR only for low-income countries.

The results in Table 5 indicated that the causal relation between $\mathrm{HE}$ and $\mathrm{HO}$ depends on income level, type of variables used to measure $\mathrm{HO}$ and choice of estimation techniques. Therefore, the results of the past studies that concluded a significant causal relationship should be interpreted with caution.

Table 4 Fully modified ordinary least square (FMOLS) test

\begin{tabular}{|c|c|c|c|c|c|c|c|c|}
\hline \multirow{2}{*}{$\begin{array}{l}\text { Dep. Variables } \\
\text { Income Groups }\end{array}$} & \multicolumn{2}{|l|}{ IMR } & \multicolumn{2}{|l|}{ MMR } & \multicolumn{2}{|l|}{ U5MR } & \multicolumn{2}{|l|}{ LFE } \\
\hline & Coef. & SE & $\overline{\text { Coef. }}$ & SE & Coef. & SE & Coef. & SE \\
\hline$\overline{\mathrm{GL}}$ & $-0.003^{*}$ & 0.000 & $-0.024^{*}$ & 0.004 & $-0.004^{*}$ & 0.001 & $0.092^{*}$ & $\overline{0.006}$ \\
\hline LY & $-0.005^{*}$ & 0.001 & 0.059 & 0.306 & $-0.080^{*}$ & 0.047 & $0.930^{*}$ & 0.180 \\
\hline LM & $-0.025^{*}$ & 0.003 & 0.034 & 0.028 & $-0.040^{*}$ & 0.004 & $0.523^{*}$ & 0.085 \\
\hline $\mathrm{HM}$ & $-0.005^{*}$ & 0.001 & $-0.100^{*}$ & 0.017 & $-0.006^{*}$ & 0.002 & $0.209^{*}$ & 0.020 \\
\hline $\mathrm{HY}$ & $-0.002^{*}$ & 0.001 & $-0.036^{*}$ & 0.011 & $-0.000^{*}$ & 0.000 & $0.014^{*}$ & 0.003 \\
\hline
\end{tabular}

Notes: ${ }^{*}$ Indicates significant at $5 \%$ confidence interval 
Table $\mathbf{5}$ Granger causality and non-causality tests

\begin{tabular}{|c|c|c|c|c|c|c|}
\hline & \multicolumn{2}{|c|}{ Granger causality test } & \multicolumn{2}{|c|}{ DH non-causality approach } & \multicolumn{2}{|c|}{ TY non-causality approach } \\
\hline & HE to IMR & IMR to HE & HE to IMR & IMR to HE & HE to IMR & IMR to HE \\
\hline & Z-value & Z-value & Z-value & Z-value & Z-value & Z-value \\
\hline $\mathrm{GL}$ & 2.91 & $14.37^{*}$ & $9.29^{*}$ & $10.31^{*}$ & 6.69 & 7.32 \\
\hline LY & $7.77^{*}$ & 0.43 & $3.19^{*}$ & $5.97^{*}$ & $4.57^{*}$ & $12.31^{*}$ \\
\hline LM & 4.25 & $14.10^{*}$ & $3.02^{*}$ & $3.06^{*}$ & $5.79^{*}$ & 1.94 \\
\hline HM & 2.88 & 1.92 & 1.54 & $1.65^{*}$ & 1.74 & 6.01 \\
\hline \multirow[t]{4}{*}{ HY } & $22.57^{*}$ & $30.64^{*}$ & $4.02^{*}$ & 1.22 & $12.21^{*}$ & 5.79 \\
\hline & \multicolumn{2}{|c|}{ Granger causality test } & \multicolumn{2}{|c|}{ DH non-causality approach } & \multicolumn{2}{|c|}{ TY non-causality approach } \\
\hline & HE to MMR & MMR to HE & HE to MMR & MMR to HE & HE to MMR & MMR to $\mathrm{HE}$ \\
\hline & Z-value & Z-value & Z-value & Z-value & Z-value & Z-value \\
\hline $\mathrm{GL}$ & 5.76 & $10.67^{*}$ & $3.65^{*}$ & $4.01^{*}$ & 4.12 & 3.35 \\
\hline LY & 0.20 & 1.07 & -1.64 & 1.20 & $9.43^{*}$ & 1.95 \\
\hline LM & 2.34 & 0.46 & 0.11 & -0.84 & 5.29 & 5.89 \\
\hline HM & 0.91 & 0.54 & -0.24 & -0.12 & 5.39 & 0.01 \\
\hline \multirow[t]{4}{*}{ HY } & $2.85^{*}$ & 0.56 & -0.97 & $1.78^{*}$ & 1.87 & 6.37 \\
\hline & \multicolumn{2}{|c|}{ Granger causality test } & \multicolumn{2}{|c|}{ DH non-causality approach } & \multicolumn{2}{|c|}{ TY non-causality approach } \\
\hline & HE to U5MR & U5MR to HE & HE to U5MR & U5MR to HE & HE to U5MR & U5MR to HE \\
\hline & Z-value & Z-value & Z-value & Z-value & Z-value & Z-value \\
\hline $\mathrm{GL}$ & $7.97^{*}$ & $22.07^{*}$ & $9.26^{*}$ & $12.06^{*}$ & 5.52 & 5.02 \\
\hline LY & $12.61^{*}$ & 0.55 & $4.51^{*}$ & $5.115^{*}$ & $10.19^{*}$ & $13.75^{*}$ \\
\hline LM & $8.19^{*}$ & 1.49 & $4.36^{*}$ & $6.62^{*}$ & 1.67 & 1.65 \\
\hline HM & 0.82 & 0.23 & 1.02 & 1.103 & 2.88 & 5.98 \\
\hline \multirow[t]{4}{*}{ HY } & $35.58^{*}$ & $26.51^{*}$ & $3.82^{*}$ & $2.001^{*}$ & 3.27 & 3.44 \\
\hline & \multicolumn{2}{|c|}{ Granger causality test } & \multicolumn{2}{|c|}{ DH non-causality approach } & \multicolumn{2}{|c|}{ TY non-causality approach } \\
\hline & HE to LFE & LFE to HE & HE to LFE & LFE to HE & HE to LFE & LFE to HE \\
\hline & Z-value & Z-value & Z-value & Z-value & Z-value & Z-value \\
\hline $\mathrm{GL}$ & $11.85^{*}$ & $14.33^{*}$ & $16.30^{*}$ & $22.60^{*}$ & $52.21^{*}$ & $24.92^{*}$ \\
\hline LY & 0.59 & 0.21 & $2.73^{*}$ & $31.17^{*}$ & 2.85 & 4.02 \\
\hline LM & 2.30 & 0.28 & $2.18^{*}$ & $10.13^{*}$ & 5.2 & $14.04^{*}$ \\
\hline HM & 1.32 & 0.56 & 1.78 & $37.38^{*}$ & 10.46 & $13.42^{*}$ \\
\hline HY & 0.00 & 1.28 & $13.25^{*}$ & $19.62^{*}$ & $33.34^{*}$ & 5.21 \\
\hline
\end{tabular}

Notes:* Indicates significant at 5\% confidence interval. Lag lengths based on Modified AIC and Modified BIC lag selection criteria

\section{Diagnostic tests}

Several diagnostic tests were performed to investigate key characteristics of the data. The diagnostic tests reveals that the model with LFE (dependent variable) and HE (independent variable) has first order serial correlation and the residuals are not normal. Therefore, no substantive conclusion about the relationship between LFE and HE can be made. Table 6 presents all the results of the diagnostic tests. The Wooldridge test for autocorrelation rejected the null hypothesis of first order autocorrelation for all models at all income levels except for the model of LFE and HE. The Pesaran CD test significantly accepts the alternative hypothesis of the presence of the cross-section dependence among the panel data. Moreover, the modified Wald test also found that the panel data contains heterogeneity. Lastly, the residual normality test on the panel data accepts the null hypothesis, therefore, it is concluded that the residuals of the panel data are normally distributed.

A vector autoregressive normality test (not reported) was also undertaken and all the eigenvalues indicated that the panel VAR is stable for all models.

\section{Impulse response and variance decomposition tests}

The Granger causality test suggested significant impact and direction of causality among the variables in the model but the results do not represent the construction or duration of these impacts. The results of the impulse responses of the variables are presented in Fig. 1 and variances decompositions in Table 7. The results of the IRF test indicated that any shock to HE per capita increases IMR and U5MR but the effects die down after two to three periods. Interestingly, MMR, except in low-income countries, reacted negatively to 
Table 6 Key diagnostic tests

\begin{tabular}{|c|c|c|c|c|c|c|c|c|}
\hline & \multicolumn{8}{|c|}{ Wooldridge test for autocorrelation } \\
\hline & \multicolumn{2}{|l|}{ HE -IMR } & \multicolumn{2}{|l|}{ HE-MMR } & \multicolumn{2}{|c|}{$\mathrm{HE}-\mathrm{U} 5 \mathrm{MR}$} & \multicolumn{2}{|l|}{ HE-LFE } \\
\hline & Z-value & $p$-value & Z-value & $p$-value & Z-value & $p$-value & Z-value & $p$-value \\
\hline$\overline{G L}$ & 2.54 & 0.113 & 0.84 & 0.359 & 3.76 & 0.054 & 27.97 & 0.000 \\
\hline LY & 7.12 & 0.067 & 4.92 & 0.073 & 3.36 & 0.075 & 62.56 & 0.000 \\
\hline LM & 1.39 & 0.243 & 1.46 & 0.232 & 5.16 & 0.068 & 1.13 & 0.293 \\
\hline $\mathrm{HM}$ & 2.54 & 0.112 & 0.845 & 0.359 & 3.75 & 0.054 & 0.392 & 0.532 \\
\hline \multirow[t]{4}{*}{ HY } & 3.74 & 0.056 & 0.092 & 0.763 & 12.76 & 0.081 & 15.89 & 0.000 \\
\hline & \multicolumn{4}{|c|}{ Pesaran CD test } & \multicolumn{4}{|c|}{ Modified Wald heteroscedasticity test } \\
\hline & \multicolumn{2}{|c|}{ HE to IMR HE-MMR } & \multicolumn{2}{|c|}{ HE -U5MR HE-LFE } & \multicolumn{2}{|c|}{ HE to IMR HE-MMR } & \multicolumn{2}{|c|}{ HE -U5MR HE-LFE } \\
\hline & Z-value & Z-value & Z-value & Z-value & $p$-value & $p$-value & $p$-value & $p$-value \\
\hline $\mathrm{GL}$ & $0.45^{*}$ & $0.25^{*}$ & $0.48^{*}$ & $0.86^{*}$ & 0.000 & 0.000 & 0.000 & 0.000 \\
\hline LY & $0.45^{*}$ & $0.37^{*}$ & $0.43^{*}$ & 0.54 & 0.000 & 0.000 & 0.000 & 0.000 \\
\hline LM & $0.54^{*}$ & $0.29^{*}$ & $0.56^{*}$ & $0.89^{*}$ & 0.000 & 0.000 & 0.000 & 0.000 \\
\hline $\mathrm{HM}$ & $0.46^{*}$ & $0.23^{*}$ & $0.49^{*}$ & $0.26^{*}$ & 0.000 & 0.000 & 0.000 & 0.000 \\
\hline $\mathrm{HY}$ & $0.41^{*}$ & $0.72^{*}$ & $0.45^{*}$ & $0.68^{*}$ & 0.000 & 0.000 & 0.000 & 0.000 \\
\hline \multicolumn{9}{|c|}{ Residual Normality test } \\
\hline & Skewness & Kurtosis & & & & & & \\
\hline & $p$-value & $p$-value & & & & & & \\
\hline IMR- HE & 0.273 & 0.167 & & & & & & \\
\hline MMR-HE & 0.095 & 0.205 & & & & & & \\
\hline U5MR-HE & 0.774 & 0.165 & & & & & & \\
\hline LFE-HE & 0.756 & 0.002 & & & & & & \\
\hline
\end{tabular}

any shock to HE. Expectedly, the results showed that $\mathrm{HO}$ of low-income countries are more vulnerable to any shock in the model. Again, any shocks to HE have more impact on U5MR than the other measures of $\mathrm{HO}$.

The results in Table 7 are consistent with the findings of the IRFs and reveal that HE can explain future variations in U5MR more than any other measures of $\mathrm{HO}$ at all income levels. HE can explain as much as $17.21 \%$ of the variation in IMR after the 12th year for low-income countries. Results of the FEVD test showed that the relationship between MMR and HE is insignificant at all income levels.

\section{Robustness to alternative specifications}

To examine the robustness of the findings, this study estimated two alternative hypotheses by adding a variable to the model and by identifying the impact of a common shock on the relationship. First, the ARDL and FMOLS tests were conducted by incorporating total factor productivity (TFP) into the model. Previous studies have concluded that improvement in TFP has a positive and significant influence on $\mathrm{HO}[67,68]$. A higher level of TFP indicates the efficiency with which resources are utilised [69]. Hence, countries with higher TFP often produce better $\mathrm{HO}$ with lower spending on health. The results (Tables 8 and 9 in Appendix) showed no significant difference in the association between HE and HO when TFP was controlled for except for the variable MMR. HE and MMR demonstrated a significant and negative relationship for lower, lower-middle and higher-middle income countries. For detailed definition of TFP and the source of data see the 'Conference Board Total Economy Database' [70].

Second, previous studies have concluded that the global financial crisis (GFC) of 2008 had a severe impact on health, health-related behaviours and quality of life. There is evidence to support this link for both developed countries [71, 72] as well as for developing countries $[73,74]$. These studies associated the GFC with a reduction in health funding and subsequent poor $\mathrm{HO}$ in the post GFC period. Hence, this study further investigated the long-run relationship between $\mathrm{HE}$ and $\mathrm{HO}$ by dividing the panel data into pre (1995-2008) and post (2009-2014) GFC periods. The outcomes of panel ARDL model and the FMOLS estimations for the two periods illustrate minor differences in the long-run relationship between $\mathrm{HE}$ and $\mathrm{HO}$ for middle-income countries (Tables 10 and 11 in Appendix). In particular, for the lower-middle and higher-middle income countries the IMR and U5MR show substantial long-run association with $\mathrm{HE}$ in the post GFC period only. 

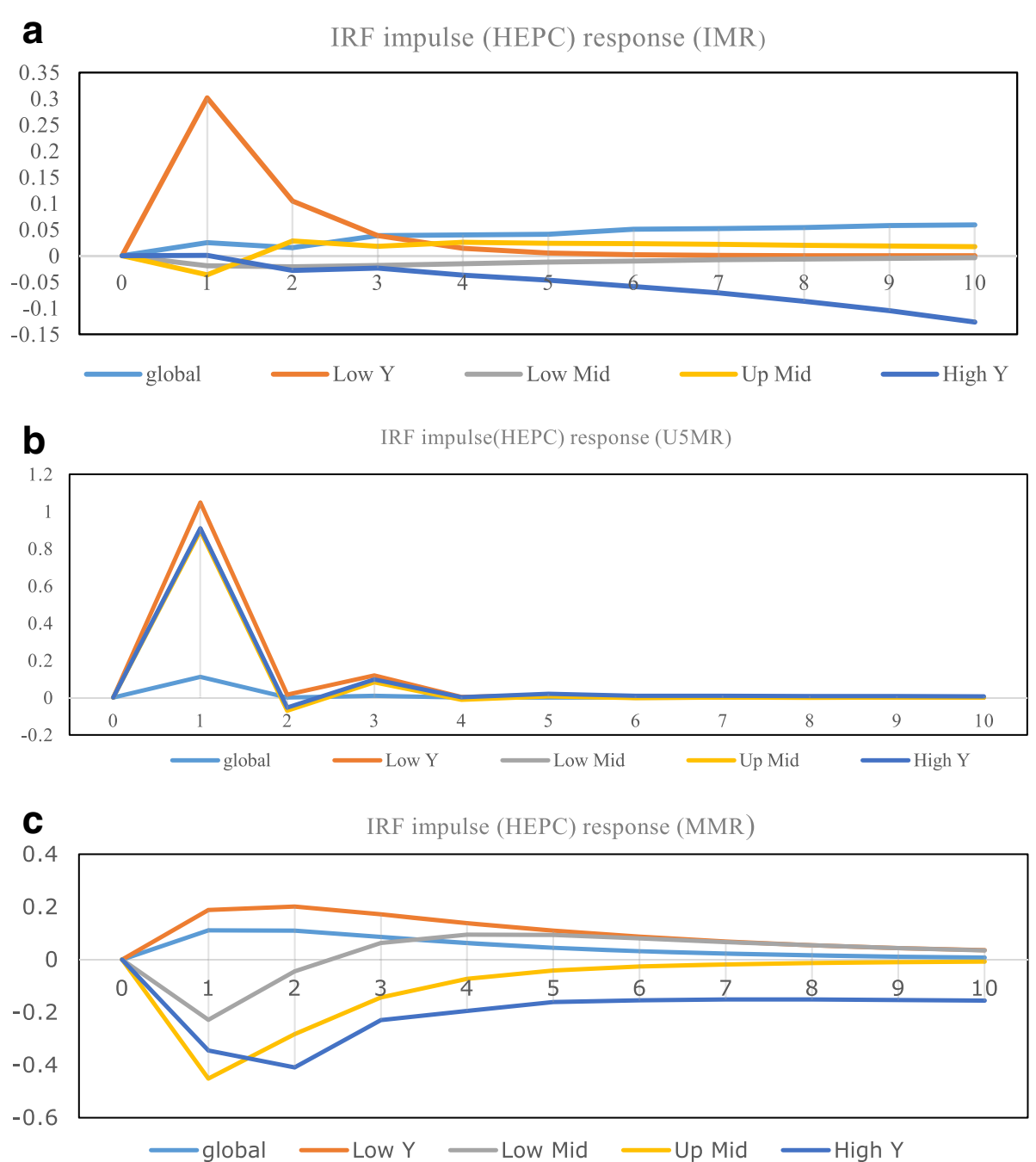

Fig. 1 Impulse response functions. Health expenditures (impulse variable) and health outcomes (response variable). a) Title: IRF (impulse HEPC and response IMR). Legends._ global _L LOW Y Low Mid _ Up Mid _ High Y b) Title: IRF (impulse HEPC and response U5MR). Legends. - global _LoW Y Low Mid _ Up Mid — High Y c) Title: IRF (impulse HEPC and response MMR). Legends - global L Low $Y$ L Low Mid U U Mid - High $Y$

\section{Discussion}

The findings indicated that the causal relationship varies significantly between low, middle and high-income countries. Several major discussion points arise.

First, the causal link between HE with IMR and U5MR is greater for low-income countries. Although there is evidence of a significant association at all income levels, the results are more consistent for low-income countries across all the measures of HO. These findings are similar to Self and Grabowski [17] and Deaton [75] who concluded that rising HE has greater influence on $\mathrm{HO}$ in low-income countries than in higher income countries. In addition, high-income countries have better $\mathrm{HO}$ because they continuously enjoy better health over a longer period of time. As IMR is already at minimum levels in these countries, rising HE has no significant influence on its further reductions.
Second, HE has no causal relation with MMR. Therefore, countries need to focus on other unobserved variables to make a substantial impact in its reduction. Gottret and Schieber [76] and Nicholas et al. [19] also reached similar conclusions. Compared to child mortality which is an outcome of primary care, MMR is viewed as secondary care which is often provided by hospitals [23]. In low-income countries, especially in rural areas, the lack of infrastructure and distance to the nearest hospital reduce access to health care services. Wagstaff [77] found that the quality of the road network can influence the impact of $\mathrm{HE}$ on $\mathrm{HO}$. In addition, it is accepted that a lack of family planning and minimum access to health care are the major causes of MMR [17]. Again, a closer look at the data reveals that MMR in high-income countries is already very low, averaging 10 deaths per 100,000 live births. Subsequently, further spending may not 
Table 7 Forecast-error variance decomposition test (income group comparison)

\begin{tabular}{|c|c|c|c|c|c|c|c|}
\hline \multicolumn{3}{|c|}{ Variance decomposition } & \multicolumn{5}{|c|}{ Impulse variable health expenditure } \\
\hline \multirow{2}{*}{$\begin{array}{l}\mathrm{LY} \\
\text { Period }\end{array}$} & \multicolumn{2}{|c|}{ Response variables } & \multirow[b]{2}{*}{ USMR } & \multirow{2}{*}{$\begin{array}{l}\text { LM } \\
\text { Period }\end{array}$} & \multicolumn{3}{|c|}{ Response variables } \\
\hline & IMR & $M M R$ & & & IMR & $M M R$ & USMR \\
\hline 0 & 0 & 0 & 0 & 0 & 0 & 0 & 0 \\
\hline 2 & 0.1516875 & 0.0168 & 0.083523 & 2 & 0.019212 & 0.006631 & 0.062427 \\
\hline 4 & 0.1717245 & 0.0408 & 0.083659 & 4 & 0.022824 & 0.016638 & 0.06754 \\
\hline 6 & 0.172093 & 0.0508 & 0.083663 & 6 & 0.02724 & 0.020663 & 0.068715 \\
\hline 8 & 0.1720995 & 0.005505 & 0.083663 & 8 & 0.030114 & 0.022065 & 0.068956 \\
\hline 10 & 0.1721 & 0.0057 & 0.083663 & 10 & 0.031903 & 0.02254 & 0.069006 \\
\hline 12 & 0.1721 & 0.005795 & 0.083663 & 12 & 0.033052 & 0.0227 & 0.069017 \\
\hline $\mathrm{HM}$ & \multicolumn{3}{|c|}{ Response variables } & HY & \multicolumn{3}{|c|}{ Response variables } \\
\hline Period & $I M R$ & $M M R$ & USMR & Period & IMR & $M M R$ & USMR \\
\hline 0 & 0 & 0 & 0 & 0 & 0 & 0 & 0 \\
\hline 2 & 0.0094175 & 0.008848 & 0.014273 & 2 & $1.69 \mathrm{E}-05$ & 0.003191 & 0.12657 \\
\hline 4 & 0.083379 & 0.011133 & 0.046812 & 2 & 0.041963 & 0.019582 & 0.161816 \\
\hline 6 & 0.102849 & 0.011687 & 0.057516 & 2 & 0.061122 & 0.030531 & 0.213393 \\
\hline 8 & 0.1067585 & 0.01194 & 0.062043 & 8 & 0.074016 & 0.047492 & 0.227842 \\
\hline 10 & 0.1075825 & 0.012068 & 0.064321 & 10 & 0.082359 & 0.061703 & 0.232503 \\
\hline 12 & 0.1077575 & 0.012136 & 0.065539 & 12 & 0.087124 & 0.07372 & 0.23381 \\
\hline
\end{tabular}

Here, GL Global, LY Low-income, LM Lower-middle, HM Higher-middle and HY High-income countries

induce any significant reduction in MMR. A further analysis of the relationship indicated that the relationship became significant for all income groups except high-income countries once TFP is accounted for in the model.

Third, ARDL and FMOLS test results indicated that HE has a positive impact on LFE in the short-run as well as in the long-run. Similar findings are evident from [14, 21]. Noticeably, the impact of HE on LFE is higher in lower income countries compared to higher income countries with better LFE. Therefore, the marginal return of HE on LFE diminishes as the LFE grows higher.

Lastly, any negative economic shock in $\mathrm{HE}$ affects $\mathrm{HO}$ in the low and lower-middle income countries to a proportionally greater extent. That means, poor countries are more exposed to negative shocks. In addition, HE can explain variations in IMR and U5MR more than the other two measures of $\mathrm{HO}$.

The variations in the relationships between $\mathrm{HE}$ and $\mathrm{HO}$ among income groups may be subject to differences in the health financing mix and level of efficiency in allocating scarce resources and providing health care services [78]. According to Self and Grabowski [17] developed countries often enjoy the virtuous cycle of good health because of higher incomes and levels of education. Previous studies have also indicated that efficient health interventions and ease of access to health care services often play a moderating role in shaping the effectiveness of the health care expenditure [14, 77]. Unfortunately, these measures vary significantly among countries of different income groups.

In addition, heterogeneity in the $\mathrm{HO}$ of the population often results from lifestyle choices (consumption of alcohol and tobacco) [79]; obesity and other chronic diseases [80]; inequality in income distribution; level of female education; ethnic diversity, and religious beliefs [14]. Others have concluded that the magnitude of the association between HE and HO depends on the availability and allocation of medical resources [81, 82] and the efficiency with which these resources are utilized [83]. For lower and middle-income countries, increases in HE on immunization and vaccination programs can substantially reduce child mortality $[29,84]$. Another key issue is to realize that there is evidence of diminishing marginal returns to growing $\mathrm{HE}$ in the health care sector for developed countries [85]. This indicates that identical amounts of $\mathrm{HE}$ in lower and middle-income countries would generate higher $\mathrm{HO}$ compared to higher income or developed countries [5]. Hence, the findings in this current study of significant heterogeneity in the relationship between HE and $\mathrm{HO}$ across income levels is justified.

Lastly, the results depend on the choice of assumptions made including, homogeneity, cross-section independence, serial correlation and residual normality. Again, the findings vary substantially on the selection of lag values, therefore, like other macroeconomic variables, measures of $\mathrm{HO}$ also depend on their values in previous years. Moreover, inappropriate diagnostic tests may lead to incorrect selection of estimation techniques and spurious results.

Some important policy implications can be drawn from the findings of the study. Firstly, the marginal impact of additional per capita health expenditure decreases as the level of expenditure increases. This is evident from the empirical results as a dollar increase in health expenditure 
in low-income countries demonstrates a greater increase in health outcomes, compared to higher income countries. Another important consideration is that mortality rates in developed countries are considerably lower consistent with a higher level of life expectancy. Therefore, these countries need to allocate additional funds (much larger than low or middle-income countries) for further improvement in health outcome as their population ages. Secondly, lower income countries are more adversely affected by negative shocks in the health care sector. Policymakers in these countries should maintain additional provisions for these shocks (disease or finance). Else, the health outcome achievements of one decade might be dissipated within a very short period of time. Thirdly, the descriptive analysis showed that countries of all income levels have experienced lower mortality and rising life expectancy during the last two decades. This indicates that low and middle-income countries will soon experience a change in their demographic structure. Existing financial mechanisms might be inadequate to support the additional demand for medical services that will arise. Lastly, lack of adequate information on health, especially in the low-income countries often makes it difficult to conduct empirical analysis and draw accurate conclusions. Governments in each country should devote resources towards high quality health data collection and make it available for further empirical investigation.

Future empirical studies should focus on analysing the relationship between health outcomes and expenditure, using country-specific data. Specifically, understanding the mediating role of good governance, level of infrastructure development, productivity, economic development and health financing mix to explain the impact of health expenditure on health outcomes.

This study also has some limitations. First, due to data unavailability the time period studied is relatively short at 20 years; second, the unavailability of a comparable health index as proxy for $\mathrm{HO}$; third, an accurate causality test on the relationship between LFE and HE could not be made as the data showed autocorrelation; fourth, the exclusion of key determinants of $\mathrm{HO}$; and finally, no control for country specific key factors influencing $\mathrm{HO}$ at different levels of income was undertaken. Moreover, from the methodological perspective, this study attempted to address some of the common problems associated with panel cointegration and panel VAR Granger causality tests. For instance, the issues of stationarity and heterogeneity of the data and cross-section dependence have been accounted for with appropriate estimation techniques using a strongly balanced panel data. Nonetheless, the results of this study should be interpreted with caution due to some underlying assumptions of the estimation techniques. For example, the Toda-Yamamoto test fails to distinguish between short-run and long-run causality [86] and the cross-section panel data does not take into account the country-specific characteristics (population, geography, governance and productivity) [87]. Due to the bivariate causality model, there may be the possibility of omitted variable bias. These issues are for future empirical research.

Lastly, this study did not account for measurement errors in the dependent and explanatory variables. Despite the ability of panel data to account for measurement errors [88], ignoring the problem especially in the explanatory variables might generate biased and inconsistent OLS estimates [31, 37, 89]. Gujarati [90] stated that a perfect solution to measurement errors in the panel data is unavailable however, there are some suggestions in the literature to account for the problem in the econometric analysis with an instrumental variable approach [89] and 'Generalised Methods of Moments' estimation [31, 37]. Therefore, future studies may use these methods to examine the association between $\mathrm{HE}$ and $\mathrm{HO}$. Any variations in findings may prove the presence of measurement error in the HE data produced by the World Bank.

\section{Conclusions}

This study examined the relationship between $\mathrm{HO}$ and $\mathrm{HE}$ for 161 countries for the period of 1995 to 2014. The findings from the panel cointegration test reveal that the $\mathrm{HO}$ measures are significantly associated with HE both in the short and long run and across all income levels. However, the short-run relation is stronger. More importantly, the heterogeneous panel DH causality test indicated that IMR and UM5R have bidirectional relationships with $\mathrm{HE}$ for all income levels except higher middle-income countries. However, according to the TY causality approach, HE Granger causes HO only for the low-income countries. This indicates that income does play an important moderating role in determining how much HE influences HO. However, the findings vary significantly due to the choice of estimation techniques.

In addition, lower income countries are more at risk of adverse $\mathrm{HO}$ because of negative shocks to HE. Variations in IMR and U5MR are better explained by HE than MMR. Lastly, the diagnostic test results vary significantly due to the choice of assumptions and lag order selection.

It is evident from the findings that increasing $\mathrm{HE}$ alone will not generate maximum $\mathrm{HO}$ at any income level. The policy makers need to look into the mix of $\mathrm{HE}$ and the allocative efficiency of the utilised resources $[12,78]$. Therefore, countries have the potential to achieve better $\mathrm{HO}$ through an efficient composition of $\mathrm{HE}$ and its financing mix. For example, rising $\mathrm{HE}$ has an insignificant impact on reducing MMR. Therefore, for better outcomes policy makers should focus on effective interventions such as family planning, increasing productivity of the health care sector and access to affordable health care. Again, theoretical and empirical research is needed to analyse the composition of $\mathrm{HE}$ and to build a comparable measure of $\mathrm{HO}$ for all countries. Improved/better HO measures like quality adjusted life years and potential years of life lost should be widely available. 


\section{Appendix}

Table 8 Mean group estimation ARDL model (with total factor productivity)

\begin{tabular}{|c|c|c|c|c|c|c|c|}
\hline \multirow{2}{*}{$\begin{array}{l}\text { Income } \\
\text { Groups }\end{array}$} & \multirow{2}{*}{$\begin{array}{l}\text { Independent } \\
\text { variables }\end{array}$} & \multicolumn{2}{|l|}{ IMR } & \multicolumn{2}{|l|}{ MMR } & \multicolumn{2}{|l|}{ U5MR } \\
\hline & & Long & Short & Long & Short & Long & Short \\
\hline LY & HEPC & $0.49 *(.15)$ & $-0.03^{*}(.004)$ & $1.7(2.6)$ & $-0.25 *(.10)$ & $-0.42^{*}(.10)$ & $-0.10 *(.00)$ \\
\hline$N=24$ & TFP & $-0.52(.41)$ & $0.003(.02)$ & $1.2^{*}(5.1)$ & $-0.21(.15)$ & $-4.1^{*}(.38)$ & $0.01 *(.03)$ \\
\hline LM & HEPC & $-0.003^{*}(.00)$ & $-0.05^{*}(.01)$ & $-0.01 *(.00)$ & $-0.01(0.01)$ & $-0.01(.00)$ & $-0.005(.02)$ \\
\hline$N=32$ & TFP & $0.04(.02)$ & $0.00(.002)$ & $0.21^{*}(.03)$ & $-0.13(0.07)$ & $0.01(.02)$ & $0.002(.01)$ \\
\hline $\mathrm{HM}$ & HEPC & $0.01(.001)$ & $-0.01(.01)$ & $-0.01 *(.00)$ & $-0.002(.00)$ & $0.01 *(.00)$ & $-0.002(.01)$ \\
\hline$N=22$ & TFP & $-0.18^{*}(.07)$ & $0.01 *(.003)$ & $0.15(.12)$ & $-0.05(.02)$ & $-0.02(.06)$ & $0.01(.01)$ \\
\hline $\mathrm{HY}$ & HEPC & $-0.002^{*}(.00)$ & $-0.001 *(.01)$ & $-0.003^{*}(.00)$ & $-0.003^{*}(.00)$ & $-0.002^{*}(.00)$ & $-0.001 *(.00)$ \\
\hline$N=37$ & TFP & $-0.01(.02)$ & $-0.002(.001)$ & $0.02(.03)$ & $-0.02(.01)$ & $-0.02(0.01)$ & $-0.001(.001)$ \\
\hline
\end{tabular}

Notes: Figures in brackets are the standard errors. ${ }^{*}$ Significant at $5 \%$ confidence interval. $\mathrm{N}$ indicates number of countries in each income groups

Table 9 Fully modified ordinary least squares test (with total factor productivity)

\begin{tabular}{|c|c|c|c|c|c|c|c|c|c|}
\hline \multirow{2}{*}{$\begin{array}{l}\text { Income } \\
\text { groups }\end{array}$} & \multirow{2}{*}{$\begin{array}{l}\text { Independent } \\
\text { variables }\end{array}$} & \multicolumn{2}{|l|}{ IMR } & \multicolumn{2}{|l|}{ MMR } & \multicolumn{2}{|l|}{ U5MR } & \multicolumn{2}{|l|}{$\underline{L F E}$} \\
\hline & & Coef. & SE & Coef. & SE & Coef. & SE & Coef. & SE \\
\hline \multirow[t]{2}{*}{ LY } & HEPC & -0.02 & 0.03 & $-0.59^{*}$ & 0.29 & $0.24^{*}$ & 0.06 & $0.04^{*}$ & 0.01 \\
\hline & TFP & $0.77^{*}$ & 0.03 & $-1.12^{*}$ & 0.04 & $-0.32^{*}$ & 0.08 & $0.74^{*}$ & 0.02 \\
\hline \multirow[t]{2}{*}{ LM } & HEPC & $-0.03^{*}$ & 0.00 & 0.01 & 0.04 & $-0.04^{*}$ & 0.01 & $0.02^{*}$ & 0.002 \\
\hline & TFP & $0.18^{*}$ & 0.02 & $0.29^{*}$ & 0.02 & $0.46^{*}$ & 0.03 & $0.18^{*}$ & 0.009 \\
\hline \multirow[t]{2}{*}{ HM } & HEPC & $-0.01^{*}$ & 0.00 & $0.03^{*}$ & 0.003 & $-0.02^{*}$ & 0.00 & -0.003 & 0.001 \\
\hline & TFP & $-0.16^{*}$ & 0.12 & $0.15^{*}$ & 0.06 & $-0.17^{*}$ & 0.02 & -0.14 & 0.014 \\
\hline \multirow[t]{2}{*}{ HY } & HEPC & -0.00 & 0.00 & $0.001^{*}$ & 0.00 & $-0.00^{*}$ & 0.00 & 0.003 & 0.000 \\
\hline & TFP & $-0.18^{*}$ & 0.00 & $-0.30^{*}$ & 0.01 & $-0.22^{*}$ & 0.01 & -0.59 & 0.012 \\
\hline
\end{tabular}

Notes: * Indicates significant at 5\% confidence interval. Coef. indicates the coefficients and SE is the standard error. Lag orders were chosen using AIC criterion

Table 10 Mean group estimation ARDL model

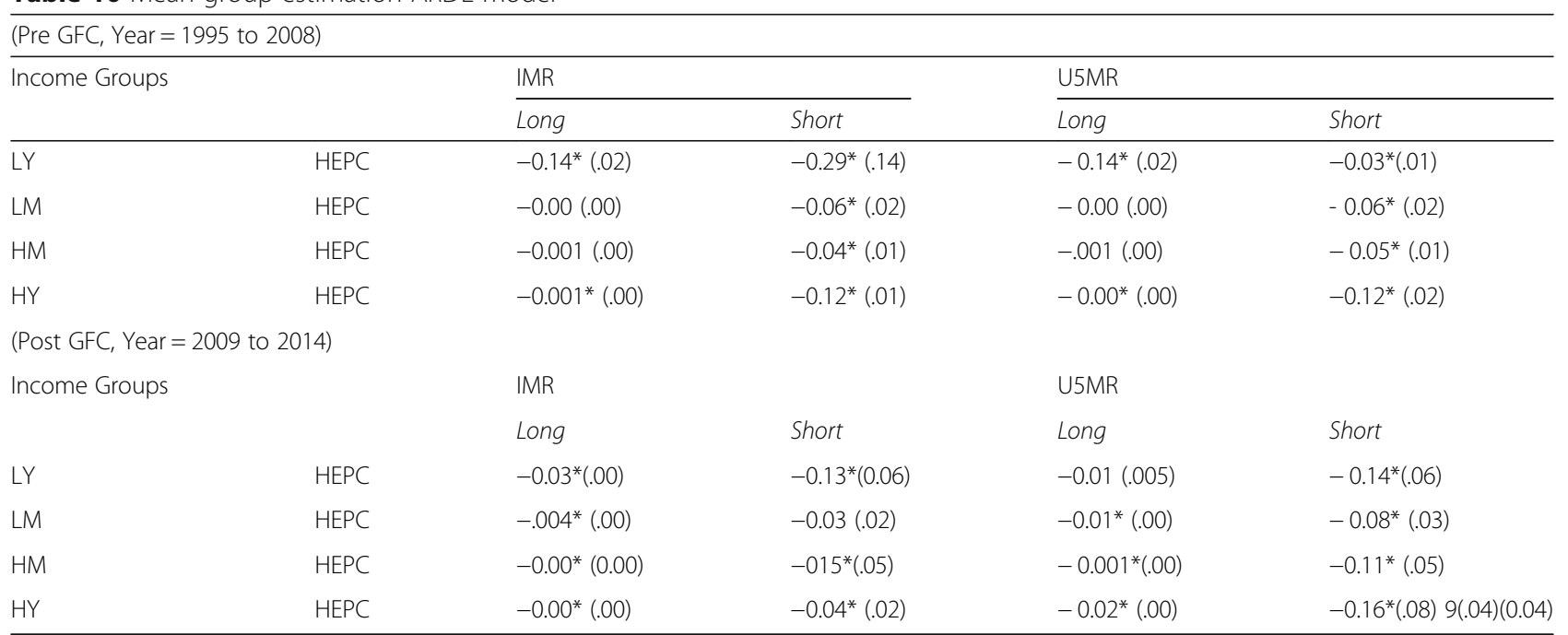


Table 11 Fully modified ordinary least squares test

\begin{tabular}{lllllll}
\hline (Pre GFC, Year = 1995 to 2008) & & & & \\
\hline Income Groups & & IMR & & & U5MR \\
\cline { 3 - 4 } & & Coef. & SE & & Coef. & SE \\
\hline LY & HEPC & $-0.20^{*}$ & 0.02 & & $-0.26^{*}$ & 0.05 \\
LM & HEPC & $-0.04^{*}$ & 0.00 & & $0.05^{*}$ & 0.01 \\
HM & HEPC & $-0.004^{*}$ & 0.00 & 0.00 & 0.00 \\
HY & HEPC & $-0.001^{*}$ & 0.00 & & $0.00^{*}$ & 0.00
\end{tabular}

(Post GFC, Year $=2009$ to 2014)

Income Groups

\begin{tabular}{lllll} 
& IMR & \multicolumn{3}{c}{ U5MR } \\
& Coef. & SE & Coef. & SE \\
HEPC & $-0.06^{*}$ & 0.01 & $-0.19^{*}$ & 0.03 \\
HEPC & $-0.01^{*}$ & 0.00 & $-0.01^{*}$ & 0.00 \\
HEPC & $-0.004^{*}$ & 0.00 & -0.02 & 0.00 \\
HEPC & $-0.00^{*}$ & 0.00 & $-0.002^{*}$ & 0.00 \\
\hline
\end{tabular}

Notes: Coef. indicates the coefficients and SE is the standard error. *

Significant at $5 \%$ confidence interval. Lag order is chosen using AIC criterion

\section{List of Countries included in the study}

The countries in this study have been divided into four groups according to the World Bank income group classifications. However, it is important to note that during this twenty year period (1995-2014) many countries improved their status from low-income to a comparatively higher-income country. For simplification of the study a country is considered a low-income country if for the majority of the time period it was a low income country. For instance, Ghana is currently a lower-middle income country. But in this study Ghana is considered a low income country as it was a low income country until the year 2009. The classification of the countries are given below:

\footnotetext{
1. High: Antigua and Barbuda, Australia, Austria, The Bahamas, Bahrain, Barbados, Belgium, Brunei Darussalam, Canada, Cyprus, Czech Republic, Denmark,Finland, France, Germany, Greece, Iceland, Ireland, Israel, Italy, Japan, Rep. Korea, Kuwait, Luxembourg, Malta, Netherlands, New Zealand, Norway, Portugal, Qatar, Saudi Arabia, Singapore, Slovenia, Spain, Sweden,Switzerland, Trinidad and Tobago, United Arab Emirates, United Kingdom,United States.

2. Upper- Argentina, Belarus, Belize, Botswana, Brazil, Bulgaria, middle: Chile, Costa Rica,Croatia, Cuba, Equatorial Guinea, Estonia, Gabon, Grenada, Hungary, Latvia, Lebanon, Lithuania, Malaysia, Mauritius, Mexico, Oman, Panama, Poland, Romania, Russian Federation, Slovak Republic, South Africa, St. Lucia, Turkey, Uruguay, Venezuela,.
}

3. Lower- Albania, Algeria, Angola, Armenia, Azerbaijan, Bhutan, middle: Bolivia, Bosnia and Herzegovina, Cabo Verde, Cameroon, China, Colombia, Rep. Congo,Djibouti, Dominican Republic, Ecuador, Arab Rep. Egypt, El Salvador, Fiji,Guatemala, Guyana, Honduras, Indonesia, Islamic Rep. Iran, Jamaica, Jordan, Kazakhstan, Kiribati, FYR Macedonia, Maldives, Moldova, Mongolia, Montenegro, Morocco, Namibia, Nicaragua, Papua New Guinea, Paraguay, Peru, Philippines, Samoa, Sri Lanka, Swaziland,
(Continued)

\begin{tabular}{ll}
\hline Thailand, Tonga, Tunisia, Turkmenistan, Ukraine, \\
Uzbekistan, Vietnam. \\
4. Low: $\quad$ Changladesh, Benin, Burkina Faso, Burundi, Cambodia, \\
Ethiopia, The Gambia, Ghana, Georgia, Guinea, Haiti, India, \\
Kenya, Kyrgyz Republic, Madagascar, Malawi, Mali, \\
Mauritania, Mozambique, Myanmar, Nepal, Niger, Nigeria, \\
Pakistan, Rwanda, Senegal, Sierra Leone, Sudan, Tajikistan, \\
Tanzania, Togo, Uganda, Rep. Yemen, Zambia.
\end{tabular}

\section{Abbreviations}

AIC: Akaike information criterion; ARDL: Autoregressive distributed lag; BIC: Bayesian information criterion; CD: Cross-section dependence; DH: Dumitrescu \& Hurlin; DY: Disposable income; FEVD: Forecast-error variance decomposition; FMOLS: Fully modified ordinary least squares; GFC: Global financial crisis; HE: Health expenditure; HEPC: Health expenditure per capita; HI: Health inputs; HO: Health outcomes; HT: Harris-Tsavails; IMR: Infant mortality rate; IPS: Im-Pesaran-Shin; IRF: Impulse response function; LFE: Life expectancy at birth; MG: Mean group; MMR: Maternal mortality rate; MWALD: Modified Wald; OECD: Organisation for economic cooperation and development; SUR: Seemingly unrelated regression; TFP: Total factor productivity; TY: Toda-Yamamoto; U5MR: Under-five mortality rate; VAR: Vector Autoregressive

\section{Acknowledgements}

The paper was part of the first author's PhD study. The PhD program was financed by the University of Southern Queensland, Australia [USQ International Stipend Research Scholarship \& USQ International Fees Research Scholarship].

We would also like to thank the reviewers for their valuable comments.

\begin{tabular}{ll}
\hline Authors name & Date \\
\hline Rezwanul Hasan Rana & $09 / 06 / 2018$ \\
Associate Prof. Khorshed Alam & $09 / 06 / 2018$ \\
Prof. Jeff Gow & $09 / 06 / 2018$
\end{tabular}

\section{Availability of data and materials}

The source of the data is the 'World Development Indicators' database published by the 'World Bank'. All the data are publicly available from the following link of the above mentioned database,

http://databank. worldbank.org/data/reports.aspx?source=world-developmentindicators

In addition, the complete structured dataset used in this study are available from the corresponding author on reasonable request. Again, we declare to publish the entire raw dataset for the readers, if and when the paper is accepted for publication,

\section{Authors' contributions}

RHR designed the study, conducted statistical analysis and prepared the initial draft of the manuscript. KA assisted in designing the study, supervised data analysis and the writing of the manuscript. JG updated the research design and reviewed the article. All authors read and approved the final manuscript.

Ethics approval and consent to participate

Not applicable.

\section{Consent for publication}

Not applicable.

\section{Competing interests}

The authors declare that they have no competing interests. 


\section{Publisher's Note}

Springer Nature remains neutral with regard to jurisdictional claims in published maps and institutional affiliations.

\section{Author details KwaZulu-Natal, Durban, South Africa. \\ Received: 14 March 2018 Accepted: 19 June 2018 \\ Published online: 16 July 2018}

${ }^{1}$ School of Commerce, University of Southern Queensland, Toowoomba, Australia. ${ }^{2}$ School of Accounting, Economics and Finance, University of

\section{References}

1. World Development Indicators (WDI) Database. The World Bank. Washingto DC. 2016. http://databank.worldbank.org/data/reports.aspx?source=worlddevelopment-indicators. Accessed 8 June 2018.

2. World Health Organization (WHO). World Health Statistics 2015. Geneva. 2016. http://apps.who.int/iris/bitstream/handle/10665/170250/ 9789240694439_eng.pdf?sequence=1. Accessed 8 June 2018 .

3. Hitiris T, Posnett J. The determinants and effects of health expenditure in developed countries. J Health Econ. 1992;11:173-81.

4. Or Z. Determinants of health outcomes in industrialised countries: a pooled, cross-country, time-series analysis. OECD Econ Stud. 2000;30:53-78.

5. Nixon J, Ulmann P. The relationship between health care expenditure and health outcomes. Evidence and caveats for a causal link. Eur J Health Econ. 2006;7:7-18.

6. van den Heuvel WJ, Olaroiu M. How important are health care expenditures for life expectancy? A comparative, european analysis. J Am Med Dir Assoc. 2017;18:276-9.

7. Anderson GF, Poullier JP. Health spending, access, and outcomes: trends in industrialized countries. Health Aff. 1999;18:178-92.

8. Bloom DE, Canning D, Sevilla J. The effect of health on economic growth: a production function approach. World Dev. 2004:32:1-13.

9. Musgrove P. Public and private roles in health: theory and financing patterns. In HNP discussion paper series; Preke AS ed. Washington, DC: The World Bank; 1996. https://openknowledge.worldbank.org/bitstream/handle/ 10986/13656/292900Musgrove0public1 private1 whole.pdf? sequence=1 Accessed 8 June 2018.

10. Gupta MS, Verhoeven M, Tiongson ME. Public spending on health care and poor. Health Econ. 2003;12:685-96.

11. Crémieux PY, Ouellette P, Pilon C. Health care spending as determinants of health outcomes. Health Econ. 1999;8:627-39.

12. Farag M, Nandakumar A, Wallack S, Hodgkin D, Gaumer G, Erbil C. Health expenditures, health outcomes and the role of good governance. Int $J$ Health Care Finance Econ. 2013;13:33-52.

13. Hall SG, Swamy PAVB, Tavlas GS. Generalized cointegration. A new concept with an application to health expenditure and health outcomes. Empir Econ. 2011:42:603-18.

14. Filmer D, Pritchett $L$. The impact of public spending on health: does money matter? Soc Sci Med. 1999;49:1309-23.

15. Thornton J. Estimating a health production function for the US: some new evidence. Appl Econ. 2002;34:59-62.

16. Bradley EH, Elkins BR, Herrin J, Elbel B. Health and social services expenditures: associations with health outcomes. BMJ Quality \& Safety. 2011;20:826-31.

17. Self S, Grabowski R. How effective is public health expenditure in improving overall health? A cross-country analysis. Appl Econ. 2003;35:835-45.

18. Bidani B, Ravallion M. Decomposing social indicators using distributional data. J Econ. 1997;77:125-39

19. Nicholas A, Edward NA, Bernardin S. The effect of health expenditure on selected maternal and child health outcomes in sub-Saharan Africa. Int Soc Econ. 2016:43:1386-99.

20. Anyanwu JC, Erhijakpor AE. Health expenditures and health outcomes in Africa. Afr Dev Rev. 2009;21:400-33.

21. Jakovljevic MB, Vukovic M, Fontanesi J. Life expectancy and health expenditure evolution in Eastern Europe-DiD and DEA analysis. Expert Review of Pharmacoeconomics \& Outcomes Research. 2016:16:537-46.

22. Vavken P, Pagenstert G, Grimm C, Dorotka R. Does increased health care spending afford better health care outcomes? Swiss Med Wkly. 2012;142:w13589.
23. Bokhari FA, Gai Y, Gottret P. Government health expenditures and health outcomes. Health Econ. 2007;16:257-73.

24. Farag M, NandaKumar A, Wallack S, Hodgkin D, Gaumer G, Erbil C. The income elasticity of health care spending in developing and developed countries. Int J Health Care Finance Econ. 2012;12:145-62.

25. Durlauf SN, Johnson PA, Temple JR. Growth econometrics. Handbook of Economic Growth. 2005;1:555-677.

26. Bai J, Ng S. Panel unit root tests with cross-section dependence: a further investigation. Econometric Theory. 2010;26:1088-114.

27. Wang P, Econometrics F. 2nd edn. New York: Routledge; 2008.

28. Grossman M. On the concept of health capital and the demand for health J Polit Econ. 1972;80:223-55.

29. World Health Organization (WHO). Global Health Observatory data repository. Geneva. 2016. http://apps.who.int/gho/data/view.main. GHEDCHEpcUSSHA2011WBv?lang=en. Accessed 25 Apr 2017.

30. Wang L. Determinants of child mortality in LDCs: empirical findings from demographic and health surveys. Health Policy. 2003:65:277-99.

31. Wooldridge JM. Econometric Analysis of Cross Section and Panel Data. 2nd ed. London: MIT Press; 2010.

32. Pesaran MH. Estimation and inference in large heterogeneous panels with a multifactor error structure. Econometrica. 2006;74:967-1012.

33. Chudik A, Pesaran MH, Tosetti E. Weak and strong cross-section dependence and estimation of large panels. Econ J 2011, 14

34. Chudik A, Pesaran MH. Common correlated effects estimation of heterogeneous dynamic panel data models with weakly exogenous regressors. J Econ. 2015;188:393-420.

35. Phillips PC, Sul D. Dynamic panel estimation and homogeneity testing under cross section dependence. Econ J. 2003:6:217-59.

36. Sarafidis $V$, Yamagata $T$, Robertson D. A test of cross section dependence for a linear dynamic panel model with regressors. J Econ. 2009:148:149-61.

37. Baltagi B. Econometric Analysis of Panel Data. 4th ed. Chichester: John Wiley \& Sons; 2008

38. Frees EW. Longitudinal and panel data: Analysis and applications for the social sciences. 1st ed. Cambridge: Cambridge University Press; 2004.

39. Hauck $K$, Zhang $X$. Heterogeneity in the effect of common shocks on healthcare expenditure growth. Health Econ. 2016;25:1090-103.

40. Hsiao C. Panel data analysis—advantages and challenges. TEST. 2007;16:1-22.

41. Pesaran $\mathrm{MH}$. A simple panel unit root test in the presence of cross-section dependence. J Appl Econ. 2007;22:265-312.

42. Baltagi $\mathrm{BH}$, Moscone F. Health care expenditure and income in the OECD reconsidered: evidence from panel data. Econ Model. 2010;27:804-11.

43. Harris RD, Tzavalis E. Inference for unit roots in dynamic panels where the time dimension is fixed. J Econ. 1999;91:201-26.

44. Pesaran MH, Shin Y, Smith RJ. Bounds testing approaches to the analysis of level relationships. J Appl Econ. 2001:16:289-326.

45. Pesaran $\mathbf{M H}$, Smith R. Estimating long-run relationships from dynamic heterogeneous panels. J Econ. 1995;68:79-113.

46. Pesaran $\mathrm{MH}$, Shin $\mathrm{Y}$, Smith RP. Pooled mean group estimation of dynamic heterogeneous panels. J Am Stat Assoc. 1999:94:621-34.

47. Pedroni P. Fully modified OLS for heterogeneous cointegrated panels nonstationary panels, panel cointegration, and dynamic panels. Elsevier. 2001;15:93-130

48. Hansen BE, Phillips PC. Estimation and inference in models of cointegration: a simulation study. Adv Econ. 1990;8:225-48.

49. Khan MA, Abbas F. The dynamics of electricity demand in Pakistan: a panel cointegration analysis. Renew Sust Energ Rev. 2016;65:1159-78.

50. Liddle B. The importance of energy quality in energy intensive manufacturing: evidence from panel cointegration and panel FMOLS. Energy Econ. 2012;34:1819-25.

51. Salahuddin M, Alam K. Internet usage, electricity consumption and economic growth in Australia: a time series evidence. Telematics Inform. 2015:32:862-78.

52. Toda HY, Yamamoto T. Statistical inference in vector autoregressions with possibly integrated processes. J Econ. 1995;66:225-50.

53. Dumitrescu E-I, Hurlin C. Testing for granger non-causality in heterogeneous panels. Econ Model. 2012;29:1450-60.

54. Granger CW. Investigating causal relations by econometric models and cross-spectral methods. Econometrica: J Econometric Soc. 1969;37:424-38.

55. Furuoka F. Financial development and energy consumption: evidence from a heterogeneous panel of Asian countries. Renew Sust Energ Rev. 2015:52:430-44. 
56. Menard AR, Weill L. Understanding the link between aid and corruption: a causality analysis. Econ Syst. 2016;40:260-72.

57. Mavrotas G, Kelly R. Old wine in new bottles: testing causality between savings and growth. Manch Sch. 2001;69:97-105.

58. Wolde-Rufael Y. Electricity consumption and economic growth: a time series experience for 17 African countries. Energy Policy. 2006;34:1106-14.

59. Rambaldi AN, Doran HE. Testing for granger non-causality in cointegrated system made easy. In: Working Papers in Econometrics and Applied Statistics No 88. Australia: University of new England; 1996.

60. Swanson NR, Granger CW. Impulse response functions based on a causal approach to residual orthogonalization in vector autoregressions. J Am Stat Assoc. 1997;92:357-67.

61. Sims CA. Macroeconomics and reality. Econometrica: J Econ Soc. 1980:1-48.

62. Brooks C. Introductory Econometrics for Finance. 2nd ed. Cambridge: Cambridge University Press; 2014.

63. Lütkepohl H, Krätzig M. Applied time series econometrics. Cambridge: Cambridge University Press; 2004.

64. Pesaran MH. General diagnostic tests for cross section dependence in panels.In Cambridge working paper in Economics. Faculty of Economics, University of Cambridge; 2004.

65. De Hoyos RE, Sarafidis V. Testing for cross-sectional dependence in paneldata models. Stata J. 2006;6:482.

66. Galvao AF, Montes-Rojas G, Sosa-Escudero W, Wang L. Tests for skewness and kurtosis in the one-way error component model. J Multivar Anal. 2013;122:35-52.

67. Cutler DM. Your money or your life: strong medicine for America's health care system. London: Oxford University Press; 2005.

68. Skinner J, Staiger D. Technology diffusion and productivity growth in health care. Review of Economics and Statistics. 2015;97:951-64.

69. Comin D. Total factor productivity. In: Economic growth. London: Springer; 2010. p. 260-3.

70. The Conference Board Total Economy Database. Growth Accounting and Total Factor Productivity, 1990-2016. https://www.conference-board.org/ data/economydatabase/index.cfm?id=27762. Accessed 10 Jan 2018.

71. Karanikolos M, Heino P, McKee M, Stuckler D, Legido-Quigley H. Effects of the global financial crisis on health in high-income OECD countries: a narrative review. Int J Health Serv. 2016;46:208-40.

72. Rajmil L, de Sanmamed MJF, Choonara I, Faresjö T, Hjern A, Kozyrskyj AL, et al. Impact of the 2008 economic and financial crisis on child health: a systematic review. Int J Environ Res Public Health. 2014;11:6528-46.

73. Leach-Kemon K, Chou DP, Schneider MT, Tardif A, Dieleman JL, Brooks BP, et al. The global financial crisis has led to a slowdown in growth of funding to improve health in many developing countries. Health Aff. 2011;31:228-35.

74. Friedman J, Schady N. How many more infants are likely to die in Africa as a result of the global financial crisis? The World Bank policy research working paper no. 5023. New York; 2009.

75. Deaton A. Relative deprivation, Inequality, and mortality. National Bureau of economic research working paper no. 8099, Cambridge; 2001

76. Gottret PE, revisited SGH f. A practitioner's guide. Washington, DC: World Bank publications; 2006.

77. Wagstaff A. The millennium development goals for health: Rising to the challenges. Washington, DC: World Bank Publications; 2004.

78. Berger MC, Messer J. Public financing of health expenditures, insurance, and health outcomes. Appl Econ. 2002;34:2105-13.

79. Cochrane AL, St Leger A, Moore F. Health service input and mortality output in developed countries. J Epidemiol Community Health. 1978;32:200-5.

80. Habibov N. What determines healthcare utilization and related out-ofpocket expenditures in Tajikistan? Lessons from a national survey. Int Public Health. 2009;54:260-6.

81. Liu J, Shi L, Khan M, Xu L, Wang L. Trends of out-of-pocket expenditure for influenza in China health and nutrition survey during 1989-2006. Int J Public Health. 2012;57:193-8.

82. Wu LA, Kanitz E, Crumly J, D'Ancona F, Strikas RA. Adult immunization policies in advanced economies: vaccination recommendations, financing, and vaccination coverage. Int J Public Health. 2013;58:865-74.

83. Aisa R, Clemente J, Pueyo F. The influence of (public) health expenditure on longevity. Int J Public Health. 2014;59:867-75.

84. Gani A. Health care financing and health outcomes in Pacific Island countries. Health Policy Plan. 2008;24:72-81.

85. Sachs JD, Warner AM. Sources of slow growth in African economies. Afr Econ. 1997;6:335-76.
86. Lin JL. Notes on testing causality. Institute of Economics, Academia Sinica, Department of Economics, National Chengchi University. Taiwan: 2008. http://faculty.ndhu.edu.tw/ jlin/files/causality_slide.pdf. Accesssed on $12^{\text {th }}$ December 2017.

87. Hatemi JA, Irandoust M. Time-series evidence for Balassa's export-led growth hypothesis. J Int Trade Econ Development. 2000;9:355-65.

88. Griliches Z, Hausman JA. Errors in variables in panel data. J Econ. 1986:31:93-118.

89. Gujarati DN, Porter DC. Essentials of econometrics. New York: McGraw-Hill; 1999.

90. Gujarati DN. Basic Econometrics. New York: Tata McGraw-hill Education; 2009.

\section{Ready to submit your research? Choose BMC and benefit from:}

- fast, convenient online submission

- thorough peer review by experienced researchers in your field

- rapid publication on acceptance

- support for research data, including large and complex data types

- gold Open Access which fosters wider collaboration and increased citations

- maximum visibility for your research: over $100 \mathrm{M}$ website views per year

At BMC, research is always in progress.

Learn more biomedcentral.com/submissions 